\title{
Serial comprehensive geriatric evaluation in older head and neck cancer patients undergoing radiotherapy
}

${ }^{*}$ L. Pottel ${ }^{1}$, M. Lycke ${ }^{1}$, T. Boterberg ${ }^{2}$, H. Pottel ${ }^{3}$, L. Goethals ${ }^{1}$, L. Ketelaars ${ }^{1}$, N. Van Den Noortgate ${ }^{4}$, F. Duprez $^{2}$, W. De Neve ${ }^{2}$, S. Rottey ${ }^{5}$, K. Geldhof ${ }^{6}$, K. Van Eygen ${ }^{7}$, K. Kargar-Samani ${ }^{8}$, V. Ghekiere ${ }^{9}$, S. Mohile ${ }^{10}$ and P. Debruyne $^{1}$

${ }^{1}$ Cancer Center, General Hospital Groeninge, Kortrijk, Belgium, ${ }^{2}$ Department of Radiation Oncology, Ghent University Hospital, Ghent, Belgium, ${ }^{3}$ Faculty of Medicine, Catholic University Leuven Kulak, Kortrijk, Belgium, ${ }^{4}$ Department of Geriatrics, Ghent University Hospital, Ghent, Belgium, ${ }^{5}$ Department of Medical Oncology, Ghent University Hospital, Ghent, Belgium, ${ }^{6}$ Department of Medicine, Jan Yperman Hospital, Ypres, Belgium, ${ }^{7}$ Department of Medicine, General Hospital OLV Lourdes, Waregem, Belgium, ${ }^{8}$ Department of Oncology, Centre Hospitalier de Wallonie Picarde, RHMS, Tournai, Belgium, ${ }^{9}$ Department of Geriatrics, General Hospital Groeninge, Kortrijk, Belgium, ${ }^{10}$ Department of Medicine, University of Rochester, NY, USA

Purpose of the study: Older head and neck (H\&N) cancer patients can present with significant co-morbidities whilst treatment induces additional morbidity. Comprehensive geriatric assessment (CGA) has been proposed as a key component in the treatment approach of older cancer patients. The feasibility of serial CGA during radiotherapy in older $\mathrm{H} \& \mathrm{~N}$ cancer patients was studied.

Material and methods: Patients aged $\geq 65$ years with primary $\mathrm{H} \& \mathrm{~N}$ cancer undergoing curative radiotherapy (with or without systemic treatment), were evaluated with the Vulnerable Elders Survey-13 (VES-13) and G8, and CGA as the gold standard, both at baseline (W0) and in the $4^{\text {th }}$ week (W4) of their treatment at General Hospital Groeninge or Ghent University Hospital.

Results: One hundred eligible patients with a median age of 72 (range 65-86) consented. Patients mostly presented with an advanced stage tumour $(69.0 \%$, stage III-IVB) of the larynx $(45.0 \%)$, the pharynx (34.0\%), the oral cavity (15.0\%) or involved neck nodes of an occult primary $(6.0 \%)$. Thirteen patients declined assessment in the $4^{\text {th }}$ week of therapy. At baseline, $36.8 \%, 69.0 \%$ and $71.3 \%$ of patients were defined vulnerable, based on respectively the VES-13 (cut-off $\geq 3$ ), G8 (cut-off $\leq 14$ ) and CGA (defined as exhibiting impairments in $\geq 2$ domains). Significantly more patients were considered vulnerable at week 4 by VES-13 (57.5\%, $P<0.0001)$, G8 $(92.0 \%, P<0.0001)$ and CGA $(83.9 \%, P<0.01)$. Patients presented with deficits in the following domains: co-morbidity (CIRS-G, grade 3 or 4), nutrition (MNA), community functioning (IADL), physical status (Tinetti), emotional wellbeing (GDS), self-care (ADL), and cognition (MMSE) at both points in time (Table 1). In addition, the incidence of vulnerability in the health domains included within the CGA increased during treatment, with especially deterioration of nutritional $(P<0.0001)$, functional (IADL, $P<0.0001)$, emotional $(P<0.01)$, and mental $(P<0.01)$ status.

Conclusions: Serial CGA identifies the multidimensional health problems and their evolution during radiotherapy. It indicates the need for re-evaluation of the patient's health status and could guide intensive supportive care in older patients treated for H\&N cancer. 
Table 1: Vulnerability at weeks 0 and 4 of radiotherapy in 87 evaluable patients ${ }^{\mathrm{a}}$

\begin{tabular}{|c|c|c|c|c|c|}
\hline Screening tools & $\begin{array}{c}\text { Week 0 } \\
\text { Median score } \\
{\left[Q_{1}, Q_{3}\right]} \\
\end{array}$ & $\begin{array}{c}\text { Vulnerable } \\
\text { patients W0 } \\
\mathrm{N}(\%)\end{array}$ & $\begin{array}{c}\text { Week } 4 \\
\text { Median score } \\
{\left[Q_{1}, Q_{3}\right]} \\
\end{array}$ & $\begin{array}{l}\text { Vulnerable } \\
\text { patients W4 } \\
\mathrm{N}(\%) \\
\end{array}$ & p-value \\
\hline $\begin{array}{l}\text { Vulnerable Elders Survey-13 } \\
\text { (VES- } 13 \text {; cut-off } \geq 3 \text {, range } 0-10 \text { ) }\end{array}$ & $1.0[0.0,5.0]$ & $32(36.8)$ & $4.0[1.0,6.0]$ & $50(57.5)$ & $<0.0001^{1}$ \\
\hline $\begin{array}{l}\text { G8-questionnaire } \\
\text { (G8; cut-off } \leq 14 \text {, range } 0-17 \text { ) }\end{array}$ & $13.0[10.0,15.0]$ & $60(69.0)$ & $11.0[9.0,13.0]$ & $80(92.0)$ & $<0.0001^{1}$ \\
\hline \multicolumn{6}{|l|}{ Domains within the CGA } \\
\hline $\begin{array}{l}\text { Activities of Daily Living } \\
\text { (ADL; cut-off } \leq 5 \text {, range } 0-6 \text { ) }\end{array}$ & $6.0[5.5,6.0]$ & $12(13.8)$ & $6.0[5.5,6.0]$ & $16(18.4)$ & $0.077^{1}$ \\
\hline $\begin{array}{l}\text { Instrumental Activities of Daily } \\
\text { Living (IADL; cut-off } \leq 7 \text {, range } 0 \text { - } \\
\text { 8) }\end{array}$ & $7.0[6.0,8.0]$ & $44(50.6)$ & $6.0[4.0,8.0]$ & $61(70.1)$ & $<0.0001^{1}$ \\
\hline $\begin{array}{l}\text { Mini Nutritional Assessment } \\
\text { (MNA; cut-off } \leq 23.5 \text {, range } 0-30 \text { ) }\end{array}$ & $23.5[21.0,27.0]$ & $44(50.6)$ & $21.0[18.0,23.5]$ & $66(75.9)$ & $<0.0001^{1}$ \\
\hline $\begin{array}{l}\text { Mini Mental State Examination } \\
\text { (MMSE; cut-off }<24 \text {, range } 0-30 \text { ) }\end{array}$ & $26.0[24.8,28.0]$ & $15(17.4)$ & $27.0[25.0,29.0]$ & $15(17.4)$ & $0.003^{1}$ \\
\hline $\begin{array}{l}\text { Geriatric Depression Scale } \\
\text { (GDS; cut-off } \geq 6 \text {, range } 0-15 \text { ) }\end{array}$ & $2.0[1.0,4.0]$ & $15(17.2)$ & $3.0[1.0,6.0]$ & $25(28.7)$ & $0.001^{1}$ \\
\hline $\begin{array}{l}\text { Tinetti balance and gait } \\
\text { (Tinetti; cut-off } \leq 24 \text {, range } 0 \text {-28) }\end{array}$ & $26.0[25.0,27.0]$ & $24(27.9)$ & $26.0[24.0,27.0]$ & $30(34.5)$ & $0.159^{1}$ \\
\hline $\begin{array}{l}\text { Cumulative Illness Rating Scale } \\
\text { for Geriatrics (CIRS-G)* }\end{array}$ & & $65(74.7)$ & & $68(78.2)$ & $0.250^{2}$ \\
\hline $\begin{array}{l}\text { Comprehensive Geriatric } \\
\text { Assessment (CGA)* }\end{array}$ & & $62(71.3)$ & & $73(83.9)$ & $0.007^{2}$ \\
\hline
\end{tabular}

${ }^{\text {a }}$ Only patients assessed at both dates were included in the statistical analysis; ${ }^{1}$ Wilcoxon signed rank test (comparison of numerical scores);

${ }^{2} \mathrm{Mc}$ Nemar's Exact test (comparison of proportions); $\mathrm{Q}_{1}: 25 \%$ percentile, $\mathrm{Q}_{3}: 75 \%$ percentile; * proportions, no numerical score 